\title{
A Model to Describe the Anisotropic Viscoplastic Mechanical Behavior of Fresh and Irradiated Zircaloy-4 Fuel Claddings under RIA Loading Conditions
}

\author{
Matthieu Le Saux ${ }^{1)}$, Christophe Poussard ${ }^{1)}$, Xavier Averty ${ }^{1)}$, Sébastien Carassou ${ }^{1)}$, Jacques Besson ${ }^{2)}$ \\ 1) CEA-Saclay, DEN/DMN/SEMI, 91191 Gif-Sur-Yvette, France \\ 2) Centre des Matériaux, Mines Paris, CNRS UMR 7633, BP 87, 91003 Evry, France
}

\begin{abstract}
This paper presents a unified phenomenological model to describe the anisotropic viscoplastic mechanical behavior of Cold-Worked Stress Relieved (CWSR) Zircaloy-4 fuel claddings submitted to Reactivity Initiated Accident (RIA) loading conditions. This model relies on a multiplicative viscoplastic formulation and reproduces strain hardening and plastic anisotropy of the material, including temperature, strain rate and irradiation effects within RIA typical ranges. Model parameters have been tuned using axial tensile, hoop tensile and closed-end internal pressurization tests results essentially extracted from the PROMETRA program, dedicated to the study of zirconium alloys under RIA loading conditions. Once calibrated, the model provides a reliable description of the mechanical behavior of the fresh and irradiated (fluence up to $10.10^{25} \mathrm{n} \cdot \mathrm{m}^{-2}$ ) material within large temperature (from $20^{\circ} \mathrm{C}$ up to $1100^{\circ} \mathrm{C}$ ) and strain rate ranges (from $3.10^{-4} \mathrm{~s}^{-1}$ up to $5 \mathrm{~s}^{-1}$ ), representative of the RIA spectrum.
\end{abstract}

\section{INTRODUCTION}

The need to increase fuel burnup in Pressurized Water Reactors (PWR) initiated numerous studies in the field of fuel safety research aiming at evaluating the consequences of postulated events on higher burnup fuels. Reactivity Initiated Accidents (RIA), for which the postulated initiator is the inadvertent ejection of a control rod, are among the most severe design basis accidents. This accident generates a fast energy injection in the fuel (about $50 \mathrm{~ms}$ ), leading to a prompt expansion of the fuel pellets (with thermal and possibly fission gases contributions). The surrounding cladding tube is then submitted to Pellet Clad Mechanical Interaction (PCMI), which results in a strain-controlled multiaxial mechanical loading under high strain rate (typically $1 \mathrm{~s}^{-1}$ ) associated with a high heating rate (about $10^{3 \circ} \mathrm{C} . \mathrm{s}^{-1}$ ) thermal loading. Since the clad remains at fairly low temperatures during this early stage of the transient $\left(<600^{\circ} \mathrm{C}\right.$ if starting from hot zero power conditions), the fast mechanical loading generated may cause partially brittle failures of high burnup fuel claddings, embrittled due to metal-water reactions and accumulation of irradiation damage during reactor exposure. At a later stage of the transient, a Departure of Nucleate Boiling (DNB) may occur at the clad outer surface due to the heat transferred from the pellets. Then, the cladding material could remain at high temperatures (above $800^{\circ} \mathrm{C}$ ) for several seconds, until rewetting. During this fairly long period, rod internal pressure may increase, due to fission gas release after pellet-clad gap re-opening, and lead to clad failure through pressure-controlled clad ballooning. The evaluation of the risk of rod failure during RIAs currently requires the use of transient fuel behavior codes [1]. These codes are developed in conjunction with full-scale experiments [2], in order to provide an accurate interpretation of the tests with the aim of transposing them to the reactor case.

For this, suitable models are necessary to describe the mechanical behavior of fuel claddings under RIA conditions. Several models, as well as macroscopic $[3,4,5]$ as polycrystalline $[6,7,8]$, have been proposed in the literature to simulate the mechanical behavior of zirconium alloys cladding materials. However, most of them are not appropriate in the field of RIA studies since they are usually restricted to limited temperature and strain rate ranges specific of normal or slightly off-normal conditions. Moreover, micromechanical models remain still currently too complex and prohibitive in term of computation time to be used in transient fuel behavior codes, although efforts have been made to avoid these restrictions [7]. Within this framework, the present paper proposes a macroscopic constitutive model to describe the anisotropic viscoplastic behavior of fresh and highly irradiated Cold-Worked Stress Relieved (CWSR) Zircaloy-4 fuel claddings under RIA loading conditions. Suitable out-of-pile tests results, essentially collected from the PROMETRA (TRAnsient MEchanical PROperties) program [9,10,11], have been gathered for the identification of the model parameters within temperature and strain rate ranges representative of those encountered during RIA transients.

This paper is organized as follows. First, the material under study and the selected experimental database are described and the main mechanical properties of the material are discussed. In particular, the influences of test temperature, strain rate, fluence and irradiation conditions are analyzed. Then, the formulation of the proposed model is detailed. Finally, the ability of the calibrated model to reproduce the experimental data is illustrated.

\section{EXPERIMENTAL OBSERVATIONS}

\section{Material and Experimental Database}

The material consists in CWSR Zircaloy-4 tubes, which is commonly used for fuel claddings in PWR. Its weight composition is $1.2-1.7 \% \mathrm{Sn}, 0.18-0.24 \% \mathrm{Fe}, 0.07-0.13 \% \mathrm{Cr}, 0.1-0.14 \% \mathrm{O}$, Zr balance, according to the ASTM B 350.90 specification. Before irradiation, the cladding tubes present a nominal external diameter and a thickness of $9.5 \mathrm{~mm}$ and 
$0.57 \mathrm{~mm}$, respectively. The stress-relieved state is obtained by heat treatment at a temperature lower than $500^{\circ} \mathrm{C}$. The grains then remain elongated along the rolling direction (tubes axial direction) and the density of dislocations high, resulting in high mechanical strength. The fabrication process of cladding tubes leads to the development of a strongly marked crystallographic texture of the material (typically, the $\langle c\rangle$ directions are symmetrically oriented at about $40^{\circ}$ from the tube radial direction in the radial-tangential plane).

The PROMETRA experimental database was used to study the mechanical behavior of the material under thermomechanical loading conditions representative of those generated during RIAs. This database gathers axial tensile (AT), hoop tensile (HT) and closed-end internal pressurization (IP) burst tests results for non-irradiated and irradiated materials (fluences up to about $10.10^{25} \mathrm{n} \cdot \mathrm{m}^{-2}, E>1 \mathrm{MeV}$ ). These tests were performed under high strain rate loading (from $0.01 \mathrm{~s}^{-1}$ to $5 \mathrm{~s}^{-1}$ ) within a large temperature range (from $20^{\circ} \mathrm{C}$ up to $1100^{\circ} \mathrm{C}$ ). The irradiated specimens were machined from fuel cladding tubes irradiated in French PWRs. Except for some IP samples, the oxide layer of irradiated tubes was beforehand mechanically removed. Tests were performed under constant temperature. A furnace heating technique (slow heating rate, $\sim 0.2^{\circ} \mathrm{C} / \mathrm{s}$ ) was used for tests conducted below $480^{\circ} \mathrm{C}$. For higher temperatures, fast heating techniques, using the Joule effect $\left(\sim 100^{\circ} \mathrm{C} / \mathrm{s}\right)$ for AT tests and an induction heating system $\left(\sim 200^{\circ} \mathrm{C} / \mathrm{s}\right)$ for the HT tests, were used to avoid annealing, hydrides redistribution or even recrystallization of the material (which are highly timedependent processes). For the AT and HT tests, the engineering strain and the engineering stress were respectively calculated by dividing the applied force by the initial cross section and the cross-head displacement by the initial gauge length. For IP tests, the mean engineering hoop strain in the tube thickness is equal to $\Delta D_{e} / D_{m}$, where $D_{e}$ and $D_{m}$ are respectively the external and the initial mean tube diameter, and the difference between hoop and radial stresses engineering values is given by $P D_{m} / 2 t$, where $P$ is the internal pressure and $t$ is the initial tube thickness. In conformity with the negligible contribution during RIAs of elastic strains compared to plastic strains, the present paper only focuses on the inelastic behavior of the material. Parameters such as the yield stress at $0.2 \%$ plastic strain, $S_{Y}^{0.2 \%}$, the ultimate (or maximum) stress, $S_{U}$, and the uniform elongation at the onset of necking (plastic strain which corresponds to $\left.S_{U}\right), e_{U}$, were determined on the engineering stress-strain curves. True plastic strain and true stress are denoted $\varepsilon^{p}$ and $\sigma$, respectively. Tests conducted on specimens machined in spalled areas of highly corroded claddings were not considered since hydride blisters, which significantly affect the macroscopic mechanical behavior of the material, are generally observed in those regions. Moreover, for the HT tests performed on ring specimens, only ultimate stresses have been considered as a precaution. Indeed, structural effects such as bending and friction make the determination of the hoop tensile stress-strain properties from this test complex. Nevertheless, whereas the influence of these effects seems to be significant within the elastic domain and at the onset of plasticity, one can suppose that the ultimate stress is only slightly affected. Note that an international Round Robin, currently pursued, has been launched in 2001 in order to compare the results obtained from different methods involving various sample geometries for generating hoop tensile properties [12].

Experimental results extracted from the open access $[13,14]$ and restricted literature were also used in order to enlarge the experimental database, in particular for low temperatures (from $20^{\circ} \mathrm{C}$ to $350^{\circ} \mathrm{C}$ ) and low strain rates $\left(3.10^{-4} \mathrm{~s}^{-1}\right)$. Due to confidentiality reasons, some of these data will not explicitly appear on the figures shown in this paper. The experimental database gathers 521 tests results divided as listed in Table 1. These data reveal an evident scatter, especially for the irradiated material, due to the various origins of the material and to uncertainties on irradiation and testing conditions. Furthermore, note that the evaluation of uniform elongation is tricky due to the low strain hardening of the material.

\section{Analysis of the Experimental Data}

For all testing conditions (AT, HT or IP tests), the flow stress of the fresh material normally decreases with increasing temperature, $T$, due to magnification of dislocations mobility (Fig. 1 (a)). A slight inflection can be observed between $300^{\circ} \mathrm{C}$ and $600^{\circ} \mathrm{C}$. Besides, Fig. 1 (a) shows that neutron irradiation leads to a significant hardening (i.e. increase in flow stress) of the material, due to the formation of point defect clusters (high density of irradiation induced loops) that act as obstacles against the glide of deformation dislocations $[6,15,16]$. This effect is significant at low fluences, $\phi_{t}$ ( $E>1 \mathrm{MeV}$ ), then quickly saturates beyond about $2 \cdot 10^{25} \mathrm{n} \cdot \mathrm{m}^{-2}$ (i.e. one annual cycle in PWR). The saturation is related to a balance between emergence and recombination of the irradiation defects. Amplitude of the irradiation hardening significantly decreases with increasing test temperature, in particular beyond the irradiation temperature $\left(\sim 350^{\circ} \mathrm{C}\right)$, due to a partial recovery of the out of equilibrium microstructure of the irradiated material (reduction of the point defects density and growth of the irradiation induced loops). Flow stress of the irradiated material tends towards that of the nonirradiated material at high test temperatures, for which irradiation defects are quasi-instantaneously recovered in accordance with the observations of Tomimura et al. [17].

Moreover, mechanical properties of the material depend on irradiation conditions. Irradiation temperature is not uniform along fuel cladding tubes (it varies from about $320^{\circ} \mathrm{C}$ to $380^{\circ} \mathrm{C}$ ) since the temperature of the primary coolant is higher at the upper part of the assembly. The clad oxidation kinetics is faster for the higher, warmer spans. Since the external oxide layer acts as a heat insulator, temperature of the claddings increases there more quickly. Thus, oxidation is 
Table 1. Exploited experimental database.

\begin{tabular}{ccccc}
\hline \multirow{2}{*}{ Tests } & \multicolumn{2}{c}{ Fresh material } & \multicolumn{2}{c}{ Irradiated material $^{*}$} \\
& Ranges & Number & Ranges & Number \\
\hline \multirow{2}{*}{ AT } & $20-1100^{\circ} \mathrm{C}$ & 54 & $20-1100^{\circ} \mathrm{C}$ & \multirow{2}{*}{124} \\
& $3.10^{-4}-5 \mathrm{~s}^{-1}$ & & $3.10^{-4}-5 \mathrm{~s}^{-1}$ & \\
\multirow{2}{*}{$\mathrm{HT}$} & $20-900^{\circ} \mathrm{C}$ & \multirow{2}{*}{34} & $20-600^{\circ} \mathrm{C}$ & \multirow{2}{*}{168} \\
& $3.10^{-4}-5 \mathrm{~s}^{-1}$ & & $3.10^{-4}-5 \mathrm{~s}^{-1}$ & \\
IP & $20-400^{\circ} \mathrm{C}$ & \multirow{2}{*}{59} & $20-350^{\circ} \mathrm{C}$ & \multirow{2}{*}{82} \\
& $3.10^{-4}-1.5 .10^{-2} \mathrm{~s}^{-1}$ & & $3.10^{-4}-1.5 .10^{-2} \mathrm{~s}^{-1}$ & \\
\hline
\end{tabular}

${ }^{*}$ from 1 cycle up to 5 cycles in PWR

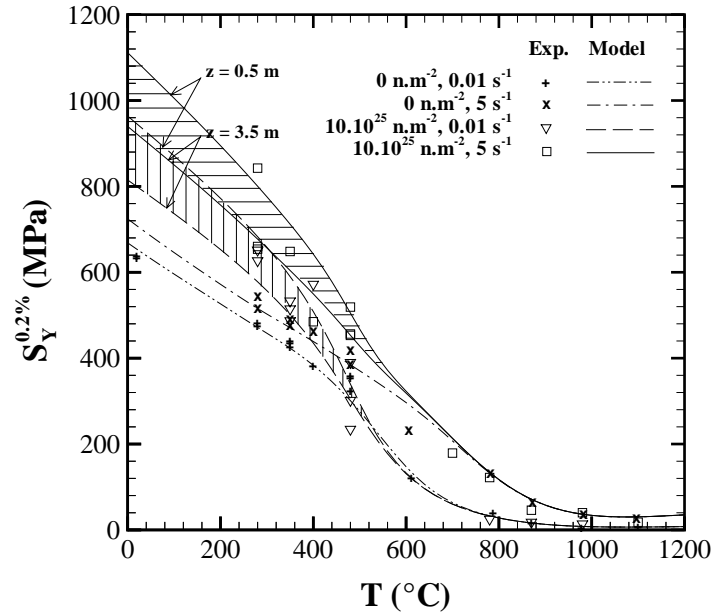

(a)

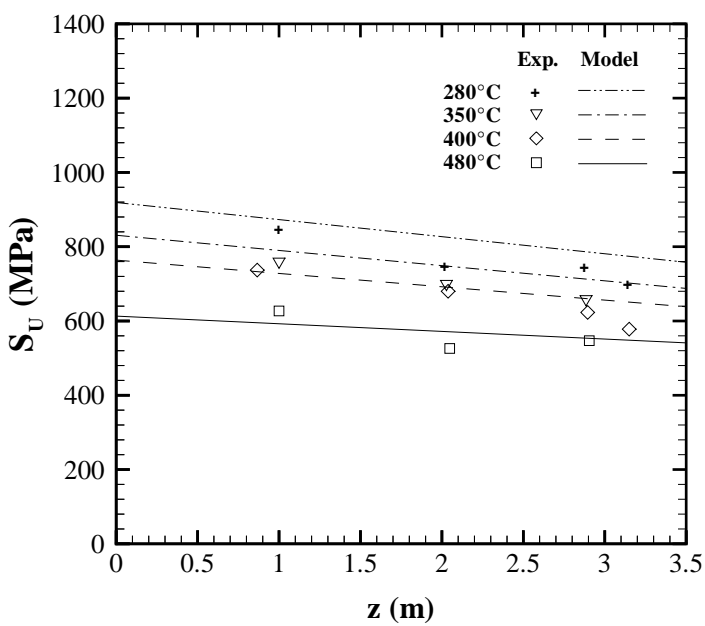

(b)

Fig. 1. (a) Variation of $0.2 \%$ yield stress as a function of temperature and strain rate for AT tests performed on the fresh material and the material irradiated for 5 cycles (fluence around $10.10^{25} \mathrm{n} \cdot \mathrm{m}^{-2}$ ). (b) Variation of maximum stress as a function of the axial position of the specimen along the cladding tubes for HT tests conducted at various temperatures under a strain rate of $5 \mathrm{~s}^{-1}$ on the material irradiated for 5 cycles.

accentuated and the thermal gradient along the claddings is intensified. Therefore, the irradiation hardening amplitude depends, in addition to fluence, on the original state of the test specimen, depending on its axial position along the tubes. Fig. 1 (b) shows that, for a same neutron fluence, the flow stress of the material decreases with increasing the axial position, $z$, in relation to the bottom of the assembly. Actually, a higher irradiation temperature allows a more efficient recombination of the point defects and thus a lower density of loops after irradiation [15]. One can expect that the axial position effect (or more specifically the irradiation temperature effect) is attenuated with increasing test temperature, in particular above the irradiation temperature. Naturally, magnitude of the variation of material strength as a function of axial position/irradiation temperature increases with increasing the irradiation time.

As shown in Fig. 2, the instantaneous strain hardening exponent of the material, $n=\left(\varepsilon^{p} / \sigma\right) \cdot\left(\partial \sigma / \partial \varepsilon^{p}\right)$, varies continuously during plastic deformation and globally decreases with increasing temperature (thermally activated dislocation cross-slip and climb). In accordance, the uniform strain continuously decreases with increasing temperature. Besides, the instantaneous strain hardening exponent decreases with increasing irradiation, in particular for plastic strains close to the uniform elongation. Indeed, independently of plastic deformation, the flow stress $\sigma$ increases with irradiation and, according to Onimus et al. [6]' observations, strain hardening rate $\partial \sigma / \partial \varepsilon^{p}$ of the irradiated material is clearly higher at the onset of plastic flow (due to the plastic strain localization at the grain scale) and rapidly decreases (channels propagation from grain to grain) to values of the same order of magnitude as the non-irradiated material's one, that decreases more gradually. Irradiation leads to a clear reduction in uniform elongation, associated to a highly localized necking (localization phenomenon known as dislocation channeling), as previously observed by Regnard et al. [16]. The irradiation effect on strain hardening behavior is reduced with increasing test temperature (irradiation damage recovery).

Fig. 1 also illustrates the strain rate sensitive strength of the material. The strain rate sensitivity, defined as the change 


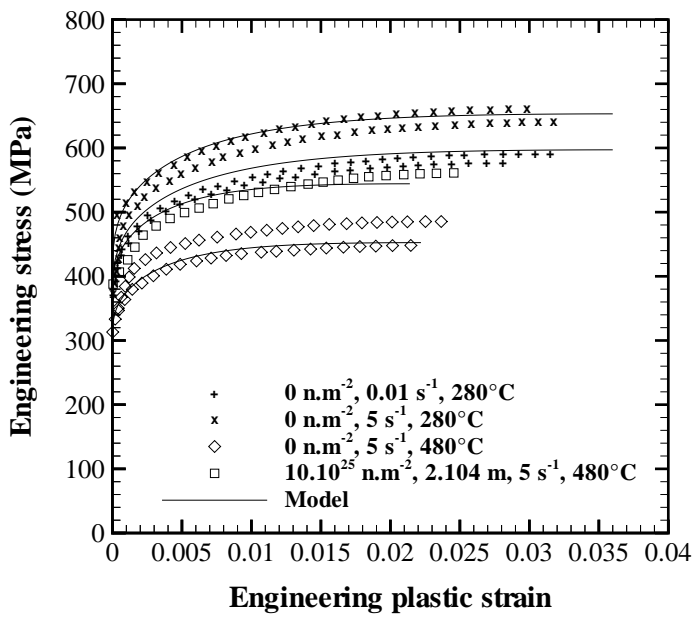

(a)

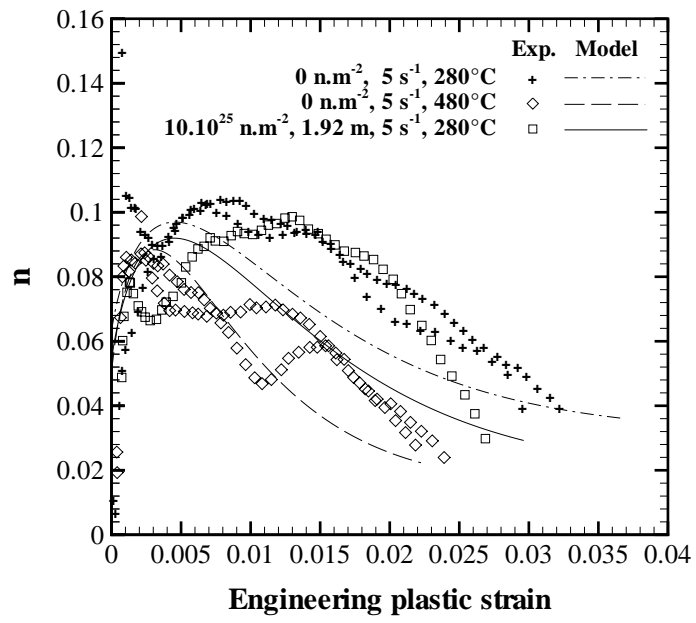

(b)

Fig. 2. (a) Experimental (symbols) and simulated (lines) engineering stress-plastic strain curves and (b) variation of the instantaneous strain hardening exponent as a function of plastic strain (up to uniform elongation) for AT tests performed under various conditions on the non-irradiated material and the material irradiated for 5 cycles.

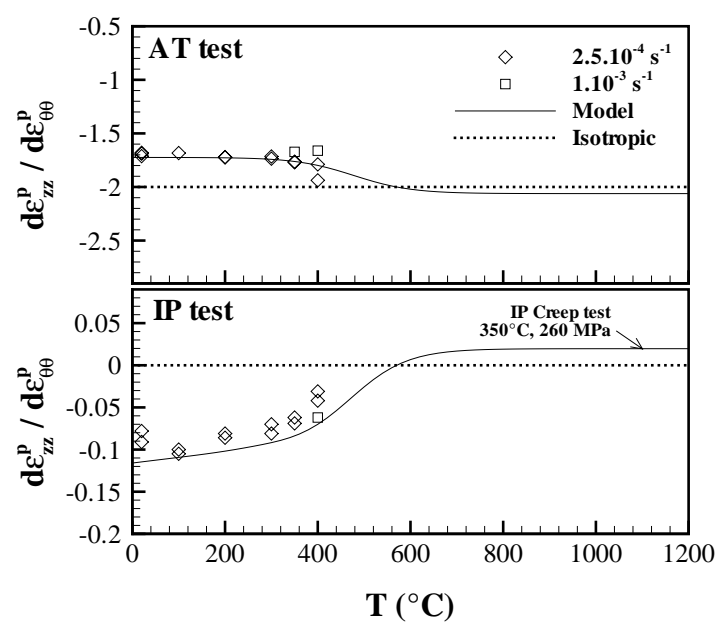

(a)

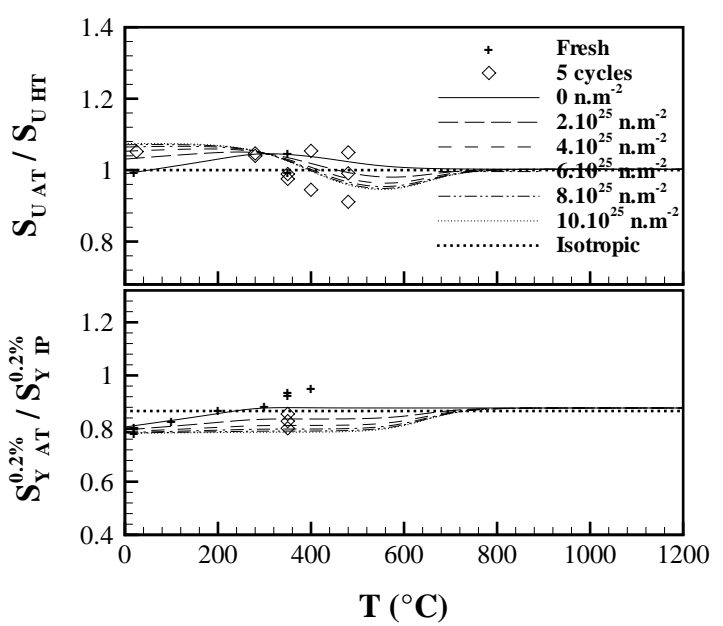

(b)

Fig. 3. (a) Variations as a function of test temperature of the ratios of axial to hoop plastic strain increments obtained during AT tests (for axial plastic strain values of 0.01 and 0.02 ) and IP tests (for hoop plastic strain values of 0.01 and 0.015) conducted on the fresh material under various strain rates. (b) Experimental (symbols) and simulated (lines) ratios of the ultimate stresses respectively measured during AT tests and HT tests and ratios of the $0.2 \%$ yield strengths respectively measured during AT tests and IP tests carried out on the fresh and the irradiated material.

in flow stress over a strain rate range, is described by the parameter $m=\partial \ln \sigma / \partial \ln \dot{\varepsilon}$ which can be approximated by $m \approx\left(\ln \sigma_{2}-\ln \sigma_{1}\right) /\left(\ln \dot{\varepsilon}_{2}-\ln \dot{\varepsilon}_{1}\right)$ where $\sigma_{1}$ and $\sigma_{2}$ are the flow stresses measured during tests conducted, for similar test temperature and irradiation conditions, under strain rates $\dot{\varepsilon}_{1}$ and $\dot{\varepsilon}_{2}$, respectively. Whatever the test temperature, the strain rate sensitivity is positive, i.e. the flow stress increases with increasing strain rate. It is nearly constant between $20^{\circ} \mathrm{C}$ and $300^{\circ} \mathrm{C}$ and increases significantly beyond. No evidence of drop in strain rate sensitivity, manifestation of dynamic strain aging (due to the mutual interaction between the oxygen solute atoms and the dislocations) generally observed around $350^{\circ} \mathrm{C}$ (depending of strain rate) in recrystallized zirconium alloys, is detected. Furthermore, it seems that irradiation accentuates strain rate sensitivity of the material for temperatures lower than about $500^{\circ} \mathrm{C}$.

Due to the hexagonal close-packed lattice of zirconium combined with the fabrication process of fuel cladding tubes, the material exhibits a strong crystallographic texture implying anisotropic, and more specifically orthotropic, mechanical 
properties in the tube reference system, i.e. radial $(r)$, hoop $(\theta)$ and axial $(z)$ directions. As shown in Fig. 3 and in accordance with the observations of Murty at al. [18], plastic anisotropy of the fresh material depends on test temperature, in particular above $300^{\circ} \mathrm{C}$. Note that the variation as a function of temperature of plastic anisotropy is more marked for lower strain rates and plastic strain levels. This evolution may be partially explained by the activation of different slip systems depending on test conditions. Whatever the test temperature and the plastic strain level, it has been established that prismatic glide is predominant for the non-irradiated material [19]. Nevertheless, other mechanisms are present: slip on the first pyramidal has been observed at high plastic strains and high temperatures and, although rarely observed, basal glide becomes significant for high temperatures (above about $500^{\circ} \mathrm{C}$ ), low strain rates and high plastic strain levels. Moreover, as illustrated in Fig. 3 (b), plastic anisotropy of the material depends on irradiation. Note that studies dealing with the influence of irradiation on the plastic anisotropy of zirconium alloys are very few [20,21]. Onimus et al. [6] observed an irradiation-induced change in the principal slip system activation. Basal slip becomes the dominant deformation mechanism for the irradiated material, since the increase under irradiation of the critical resolved shear stresses for prismatic and pyramidal slip systems is greater than for the basal slip system. In addition, one can expect that hydrides generally observed in fuel claddings irradiated in PWR may influence the anisotropy of the material.

\section{MODEL DESCRIPTION}

In order to reproduce these effects, a unified (only one type of inelastic deformation is considered) anisotropic viscoplastic model, with no stress threshold between elastic and viscoplastic regimes (and thus only appropriate for monotonous loading) and including a multiplicative plastic strain dependent strain hardening, is proposed. The total strain $\underline{\varepsilon}$ can be splitted up in an additive manner into elastic $\underline{\varepsilon}^{e}$ and viscoplastic $\underline{\varepsilon}^{p}$ parts. The elastic contribution, which is supposed to be isotropic, is described by a temperature dependent Young's modulus, $E(T)$, and a Poisson's ratio, $v$, according to the isotropic Hooke's law. The viscoplastic strains obey the normality rule $\underline{\dot{\varepsilon}}^{p}=\dot{p} \partial \bar{\sigma} / \partial \underline{\sigma}$ and are expressed as a function of the equivalent viscoplastic strain rate, $\dot{p}$, the stress tensor, $\underline{\sigma}$, and the equivalent stress, $\bar{\sigma}$. A power law type expression is used to describe the evolution of the cumulated viscoplastic strain:

$$
\dot{p}=\dot{p}_{0}\left[\frac{\bar{\sigma}\left(\underline{\sigma}, T, \phi_{t}\right)}{K\left(T, \phi_{t}, z\right) \cdot L\left(p, T, \phi_{t}\right)}\right]^{1 / m\left(T, \phi_{t}\right)}
$$

where $m$ is the strain rate sensitivity coefficient, $\dot{p}_{0}$ is the reference strain rate fixed to $1 \mathrm{~s}^{-1}, K$ is the strength coefficient and $L$ is the strain hardening coefficient. According to the experimental observations partially described in the previous section, $m$ is considered as temperature and fluence dependent, $K$ is defined as temperature, fluence and irradiation conditions dependent and $L$ is regarded as plastic strain, temperature and fluence dependent. Note that, since the irradiation temperature is not available for the majority of the tested specimens, the influence of irradiation conditions on the material behavior is expressed in term of axial position of the samples along the fuel cladding tubes, which is known for all the irradiated specimens. Nevertheless, an approximate linear relation between the irradiation temperature, $T_{i}$, and the axial position, $z$, can be established from the few irradiation temperature data available: $T_{i}=594.35+13.572 z$.

The texture-induced plastic orthotropy of the material is described by a Hill's quadratic yield criterion [22] (isotropic hardening) and the normality rule is applied:

$$
\bar{\sigma}\left(\underline{\sigma}, T, \phi_{t}\right)=\sqrt{\underline{\sigma}: \underline{\underline{H}}\left(T, \phi_{t}\right): \underline{\sigma}}, \quad \underline{\dot{\varepsilon}}^{p}=\dot{p} \underline{\underline{H}}: \frac{\underline{\sigma}}{\bar{\sigma}}
$$

where $\underline{\underline{H}}$ is a temperature and irradiation dependent symmetric fourth rank tensor. The equivalent stress has the following expression when expressed in the anisotropy principal axes, which coincide with the tube reference system axes $(r, \theta, z)$ :

$$
\bar{\sigma}=\left[H_{r r}\left(\sigma_{\theta \theta}-\sigma_{z z}\right)^{2}+H_{\theta \theta}\left(\sigma_{z z}-\sigma_{r r}\right)^{2}+H_{z z}\left(\sigma_{r r}-\sigma_{\theta \theta}\right)^{2}+2 H_{r \theta} \sigma_{r \theta}^{2}+2 H_{r z} \sigma_{r z}^{2}+2 H_{\theta z} \sigma_{\theta z}^{2}\right]^{1 / 2}
$$

Since shear components are unknown and do not intervene in the simulated mechanical tests, they are assumed to be equal to the isotropic ones, i.e. $H_{r \theta}=H_{r z}=H_{\theta z}=1.5$. In order to determine the anisotropy coefficients $H_{r r}, H_{\theta \theta}$ and $H_{z z}$, which are defined up to a multiplicative constant, the axial direction is fixed as the reference one, leading to $\bar{\sigma}=\sigma_{z z}$ and $H_{r r}+H_{\theta \theta}=1$. 
Table 2. Adjusted model parameters ( $T$ in $\mathrm{K}, \phi_{t}$ in $10^{25} \mathrm{n} \cdot \mathrm{m}^{-2}$, and $z$ in $\mathrm{m}$ ).

Elasticity:

$E(T)=1.059 .10^{11}-36.10^{6} T, v=0.342$

Strain rate sensitivity:

$$
\begin{aligned}
& m\left(T, \phi_{t}\right)=1 /\left[m_{0}(T)\left(1-m_{\phi}\left(T, \phi_{t}\right)\right)\right] \\
& m_{0}(T)=77.68 M_{0 T}(T)+4.11\left[1-M_{0 T}(T)\right] \\
& \quad M_{0 T}(T)=1 /[1+\exp (10.2(T / 692-1))] \\
& m_{\phi}\left(T, \phi_{t}\right)=0.46 \Phi\left(\phi_{t}\right) /[1+\exp (14.49(T / 870-1))]
\end{aligned}
$$

Strength:

$$
\begin{aligned}
& K\left(T, \phi_{t}, z\right)=K_{0}(T)\left[1+K_{\phi}\left(T, \phi_{t}, z\right)\right] \\
& K_{0}(T)=\left[1.409 .10^{9}-1.1558 .10^{6} T\right] K_{0 T}(T)+4.025 .10^{7}\left[1-K_{0 T}(T)\right] \\
& K_{0 T}(T)=1 /[1+\exp (6.62(T / 1007-1))] \\
& K_{\phi}\left(T, \phi_{t}, z\right)=0.42\left(1-1.76 .10^{-2} \phi_{t} z\right) \Phi\left(\phi_{t}\right) /[1+\exp (19(T / 768-1))]
\end{aligned}
$$

Anisotropy:
Irradiation damage:

$$
\Phi\left(\phi_{t}\right)=1-\exp \left(-0.3 \phi_{t}\right)
$$

Strain hardening:

$$
\begin{aligned}
& L\left(p, T, \phi_{t}\right)=\left(p+1.10^{-4}\right)^{n_{0}\left(T, \phi_{t}\right)} \exp \left(-\alpha_{n}(T) p\right) \\
& +\left(p+1.10^{-4}\right)^{n_{\infty}\left(T, \phi_{t}\right)}\left(1-\exp \left(-\alpha_{n}(T) p\right)\right) \\
& n_{i}\left(T, \phi_{t}\right)=n_{i 0}(T)\left[1-n_{i \phi}\left(T, \phi_{t}\right)\right], i=0, \infty \\
& n_{00}(T)=7.9 .10^{-2} N_{00 T}(T)+3.10^{-2}\left[1-N_{00 T}(T)\right] \\
& N_{\text {00T }}(T)=1 /[1+\exp (4(T / 620-1))] \\
& n_{0 \phi}\left(T, \phi_{t}\right)=0.24 \Phi\left(\phi_{t}\right) /[1+\exp (7(T / 630-1))] \\
& n_{\infty 0}(T)=5.10^{-2} N_{\infty 0 T}(T)+5.6 .10^{-3}\left[1-N_{\infty 0 T}(T)\right] \\
& N_{\infty 0 T}(T)=1 /[1+\exp (5(T / 590-1))] \\
& n_{\infty \phi \phi}\left(T, \phi_{t}\right)=0.63 \Phi\left(\phi_{t}\right) /[1+\exp (7(T / 630-1))] \\
& \alpha_{n}(T)=40.45 \exp \left(2.03 .10^{-3} T\right)
\end{aligned}
$$

$H_{r r}\left(T, \phi_{t}\right)=0.485+9.5 .10^{-2}\left(1-\Phi\left(\phi_{t}\right)\right) /[1+\exp (12(T / 740-1))]+0.32 \Phi\left(\phi_{t}\right) /[1+\exp (10(T / 660-1))]$

$H_{z z}\left(T, \phi_{t}\right)=0.52+\left(-0.23+4.10^{-4} T\right)\left(1-\Phi\left(\phi_{t}\right)\right) /[1+\exp (15(T / 550-1))]-0.16 \Phi\left(\phi_{t}\right) /[1+\exp (20(T / 920-1))]$

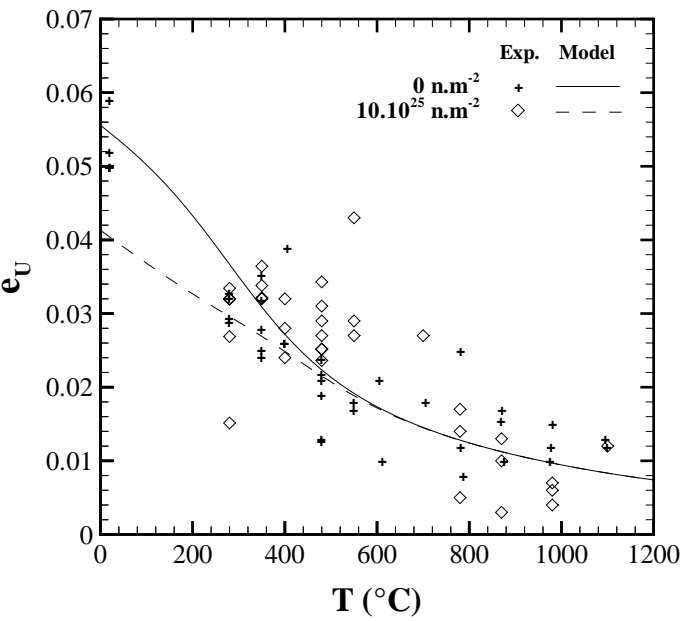

(a)

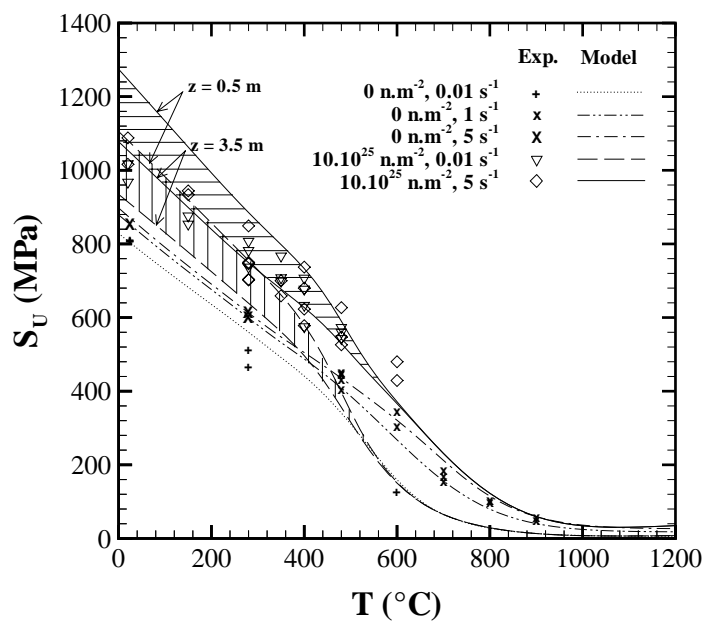

(b)

Fig. 4. (a) Variation of the uniform plastic strain as a function of temperature for AT tests performed on the nonirradiated material and the irradiated material for 5 cycles (no strain rate and irradiation conditions effect). (b) Variation of the ultimate stress as a function of temperature for HT tests performed on the fresh material and the material irradiated for 5 cycles.

\section{RESULTS AND DISCUSSION}

The proposed model includes four parameters to be adjusted: $m, K, L, \underline{H}$. Description of the strongly non-linear evolutions of material behavior with plastic strain, temperature, fluence or axial position within wide ranges requires a large number of secondary parameters. These 46 resulting secondary parameters have been identified using the experimental database defined above by applying Newton's optimization method. All functions are lower and upper bounded in order to avoid non-physical extreme parameter values and prevent numerical problems in simulation codes. 
Tuned values of the parameters are reported in Table 2. Note that, since no data related to plastic anisotropy are available for test temperatures greater than $600^{\circ} \mathrm{C}$, the anisotropy coefficients have been identified so that the ratio $d \varepsilon_{z z}^{p} / d \varepsilon_{\theta \theta}^{p}$ predicted for IP tests tends, when increasing temperature, towards the ratio value of 0.019 deduced from IP creep tests conducted at $350^{\circ} \mathrm{C}$ at a fixed stress level of $260 \mathrm{MPa}$ up to a hoop plastic strain of 0.025 [13]. Indeed, since, for a given loading direction, the activated deformation mechanisms, and consequently the macroscopic plastic anisotropy, essentially depend on the local stress level, one can expect that anisotropy of the material subjected to high temperature strain-hardening tests is closed to that deduced from creep tests conducted at moderated stress levels under moderated temperatures.

Fig. 1 (a) compares experimental and simulated evolutions of $S_{Y}^{0.2 \%}$ as a function of temperature for AT tests carried out under different strain rates on the non-irradiated material and the material irradiated for 5 cycles. The good agreement reveals the ability of the model to reproduce the influences of temperature, fluence and strain rate on the flow stress. Moreover, as depicted in Fig. 1 (b), the model accurately captures the effects of irradiation conditions on material strength. Furthermore, the temperature, irradiation and plastic strain dependent strain hardening behavior of the material (Fig. 2), including uniform elongation (Fig. 4 (a)), is correctly predicted by the model. Note in particular that the proposed formulation for the strain hardening coefficient, $L$, provides a better description of both plastic strain dependent strain hardening and uniform elongation than the classical power law type equation, $L=p^{n}$, that includes only one average strain hardening parameter $n$ and for which $\varepsilon_{U}=n$ under uniaxial tension (in accordance with the Considere's plastic instability criterion $\bar{\sigma}=\partial \bar{\sigma} / \partial p$ ). Besides, plastic anisotropy is fairly well reproduced (Fig. 3 and Fig. 4 (b)). Hence, the model provides a reasonable description of the material behavior within the studied domain, i.e. for temperatures from $20^{\circ} \mathrm{C}$ up to $1100^{\circ} \mathrm{C}$, strain rates between $3.10^{-4} \mathrm{~s}^{-1}$ and $5 \mathrm{~s}^{-1}$ and fast neutron fluences from $0 \mathrm{n} \cdot \mathrm{m}^{-2}$ up to $10.10^{25} \mathrm{n} . \mathrm{m}^{-2}$. The average value over the whole identification database of the relative error $\left|\left(\eta_{\exp }-\eta_{\text {sim }}\right) / \eta_{\exp }\right|$ between experimental quantities (yield stresses and uniform plastic strains), $\eta_{\exp }$, and the corresponding simulated values, $\eta_{\text {sim }}$, is equal to about $8 \%$ on yield stresses and $62 \%$ on uniform elongations, which is satisfactory compared to the experimental scatter (Fig. 1 (a), Fig. 2 (a) and Fig. 4). Nevertheless, prediction capability of the model is expected to decrease with increasing temperature. Indeed, the description of plastic anisotropy in particular is unsure for the upper part of the temperature range due to the lake of data pertaining to $\mathrm{HT}$ tests and IP tests, especially over $600^{\circ} \mathrm{C}$ for the irradiated material.

\section{CONCLUSIONS}

The anisotropic viscoplastic mechanical behavior of fresh and irradiated CWSR Zircaloy-4 fuel claddings has been analyzed on the basis of axial tensile, hoop tensile and closed-end internal pressurization tests results mainly extracted from the PROMETRA database, convenient in the field of RIA studies. In particular, the effects of temperature (from $20^{\circ} \mathrm{C}$ up to $1100^{\circ} \mathrm{C}$ ), strain rate (from $3.10^{-4} \mathrm{~s}^{-1}$ up to $5 \mathrm{~s}^{-1}$ ), fluence (from $0 \mathrm{n} \cdot \mathrm{m}^{-2}$ up to $10.10^{25} \mathrm{n} \cdot \mathrm{m}^{-2}$ ) and irradiation conditions (irradiation temperature or, in the absence thereof, axial position of the sample along the fuel cladding) on the inelastic properties of the material have been investigated. A phenomenological model, based on a unified multiplicative viscoplastic formulation, was developed in order to reproduce these material features. Plastic anisotropy is introduced through a temperature and irradiation dependent Hill's yield criterion. Finally, model's ability to simulate the whole experimental database mentioned above has been demonstrated.

The proposed model has been implemented into the finite element code Cast3M in order to simulate structures such as the specimens tested within the PROMETRA program. In particular, the effect of the material plastic anisotropy on local deformations has been underlined. In order to provide a better understanding of the failure mechanisms of cladding tubes during RIAs, with the aim of predicting their survivability, a Gurson-Tvergaard-Needleman (GTN) type model, coupling the deformation model described in the present paper with damage, is conjointly developed. In particular, since hydride embrittlement of fuel claddings has been identified as one of the main limiting phenomenon to burnup increase [2], the analysis of the influence of hydride precipitates on the ductile fracture (i.e. void nucleation, growth and coalescence) of cladding tubes is envisioned. Determination and identification of the model parameters will be performed by combination of numerical simulations and reliable out-of-pile experiments developed elsewhere [23], carried out under RIA loading conditions.

\section{REFERENCES}

1. Federici, E., Lamare, F., Bessiron, V., Papin, J., "The SCANAIR Code Version 3.2: Main Features and Status of Qualification," Proc. Of the Technical Committee Meeting on Fuel Behaviour Under Transient and LOCA Conditions, pp. 88-101, Halden, Norway, September 2001.

2. Papin, J., Cazalis, B., Frizonnet, J.M., Fédérici, E., Lemoine, F., "Synthesis of CABRI-RIA Tests Interpretation," Eurosafe Meeting, Paris, France, November 2003.

3. Delobelle, P., Robinet, P., Geyer, P., Bouffioux, P., "A Model to Describe the Anisotropic Viscoplastic Behaviour of Zircaloy-4 Tubes," Journal of Nuclear Materials, Vol. 238, 1996, pp. 135-162. 
4. Schäffler, I., Geyer, P., Bouffioux, P., Delobelle, P., "Thermomechanical Behavior and Modeling Between $350^{\circ} \mathrm{C}$ and $400^{\circ} \mathrm{C}$ of Zircaloy-4 Cladding Tubes From an Unirradiated State to High Fluence (0 to 85.10 $0^{24}$ n.m ${ }^{-2}, \mathrm{E}>1 \mathrm{MeV}$," Journal of Engineering Materials and Technology, Vol. 122, 2000, pp. 168-176.

5. Jernkvist, L.O., "A Model for Inelastic Deformation of Irradiated Zirconium Alloy Cladding under Transient Conditions," Proc. Of the 15th International Conference on Structural Mechanics in Reactor Technology, Seoul, Korea, August 2003.

6. Onimus, F., Béchade, J.L., Prioul, C., Pilvin, P., Monnet, I., Doriot, S., B., V., Gilbon, D., Robert, L., Legras, L., Mardon, J.P., "Plastic Deformation of Irradiated Zirconium Alloys: TEM Investigations and Micro-Mechanical Modelling," Proc. Of the 14th International Symposium on Zirconium in the Nuclear Industry, Vol. 2, pp 53-77, Stockholm, Sweden, June 2004.

7. Leclercq, S., Rousselier, G., Cailletaud, G., "A Generic Method for Modeling the Behavior of Anisotropic Metallic Materials: Application to Recrystallized Zirconium Alloys," Mechanics of Materials, Vol. 39, 2007, pp. 458-472.

8. Geyer, P., "Comportement Elasto-Viscoplastique de Tubes en Zircaloy-4 : Approche Expérimentale et Modélisation Micromécanique," Ph.D. thesis, Ecole des Mines de Paris, France, 1999.

9. Balourdet, M., Bernaudat, C., Basini, V., Hourdequin, N., "The PROMETRA Programme: Assessment of Mechanical Properties of Zircaloy-4 Fuel Cladding During an RIA," Proc. Of the 15th International Conference on Structural Mechanics in Reactor Technology, Vol. II, pp. 485-492, Seoul, Korea, August 1999.

10. Cazalis, B., Desquines, J., Bernaudat, C., Poussard, C., Averty, X., Yvon, P., "The PROMETRA Program: A Reliable Material Database for Highly Irradiated Zircaloy-4, Zirlo ${ }^{\mathrm{TM}}$ and $\mathrm{M}^{\mathrm{TM}}$ fuel claddings," Proc. Of the 18th International Conference on Structural Mechanics in Reactor Technology, Beijing, China, August 2005.

11. Desquines, J., Cazalis, B., Bernaudat, C., Poussard, C., Averty, X., Yvon, P., "Zircaloy-4 Fuel Cladding Mechanical Behavior in the Field of RIA Transients through the PROMETRA Program," Proc. Of the 14th International Symposium on Zirconium in the Nuclear Industry, Stockholm, Sweden, June 2001.

12. Billone, M.C., "The Mechanical Properties Experts Group Update on Round Robin Test Results," Argonne National Laboratory, Argonne, USA, February 2001.

13. Limon, R., Béchade, J.L., Lehmann, S., Maury, R., Soniak, A., Mardon, J.P., "Influence de la Température sur l'Anisotropie Plastique du Zircaloy-4," Proc. Of the Journées d'Etudes Propriétés - Microstructure, Le Zirconium, pp. 133-143, Saclay, France, April 1995.

14. Elbachiri, K., Crepin, J., Bretheau, T., Rebeyrolle, V., "Influence de la Microstructure des Alliages de Zirconium sur leur Sensibilité à la Vitesse de Déformation et à la Température," Proc. Of the 16ème Congrès Français de Mécanique, Nice, France, September 2003.

15. Northwood, D.O., Gilbert, R.W., Bahen, L.E., Kelly, P.M., Blake, R.G., Jostsons, A., Faulkner, D., Bell, W., Adamson, R.B., "Characterization of Neutron Irradiation Damage in Zirconium Alloys - An international "RoundRobin” Experiment," Journal of Nuclear Materials, Vol. 79, 1979, pp. 379-394

16. Regnard, C., Verhaeghe, B., Lefebvre-Joud, F., Lemaignan, C., "Activated Slip Systems and Localized Straining of Irradiated Zr Alloys in Circumferential Loadings," Proc. Of the 13th International Symposium on Zirconium in the Nuclear Industry, pp 384-399, Annecy, France, June 2001.

17. Tomimura, T., Yasuda, T., Nakatsuka, M., "Changes in Mechanical Properties of Irradiated Zircaloy-2 Fuel Cladding Due to Short Term Annealing," Journal of Nuclear Materials, Vol. 238, 1996, pp. 169-174.

18. Murty, K.L., Charit, I., "Texture Development and Anisotropic Deformation of Zircaloys," Progress in Nuclear Energy, Vol. 48, 2006, pp. 325-359.

19. Tenckhoff, E., "Review of Deformation Mechanisms, Texture, and Mechanical Anisotropy in Zirconium and Zirconium Base Alloys," Proc. Of the 14th International Symposium on Zirconium in the Nuclear Industry, Vol. 2, pp 25-50, Stockholm, Sweden, June 2004.

20. Nakatsuka, M., Nagai, M., "Reduction of Plastic Anisotropy of Zircaloy Cladding by Neutron Irradiation. I. Yield Loci Obtained from Knoop Hardness," Journal of Nuclear Science and Technology, Vol. 24, 1987, pp. 832-838.

21. Yagnik, S.K., Hermann, A., Kuo, R.C., "Ductility of Zircaloy-4 Cladding and Guide Tubes at High Fluences," Proc. Of the 14th International Symposium on Zirconium in the Nuclear Industry, Vol. 2, pp 604-631, Stockholm, Sweden, June 2004.

22. Hill, R., "The Mathematical Theory of Plasticity," Oxford, The Oxford Engineering Science Series, 1950.

23. Le Saux, M., Poussard, C., Averty, X., Sainte Catherine, C., Besson, J., "High Temperature Expansion Due to Compression Test for the Determination of a Cladding Material Failure Criterion under RIA Loading Conditions," Proc. Of the International Topical Meeting on Light Water Reactor Fuel Performance, San Francisco, California, September 2007. 